\title{
Nível de Conhecimento dos Futuros Profissionais de Contabilidade do Estado da Bahia: Uma Análise à Luz dos Conceitos Básicos Presentes nas Normas Brasileiras de Contabilidade
}

\section{Knowledge Level of Future Professionals of Accounting in the State of Bahia: An Analysis in the Light of Basic Concepts Existent in Brazilian Accounting Standards}

\section{Nivel de Conocimiento de Los Futuro Profesionales de Contabilidad del Estado Bahia: Un Análisis a la Luz de Conceptos Básicos Presentes en las Normas Contables Brasileñas}

\author{
Sonia Maria da Silva Gomes, Dr. a $^{\text {a }}$ \\ Professora do Programa de Pós-graduação (stricto sensu) em \\ Contabilidade - UFBA \\ Endereço: Faculdade de Ciências Contábeis- Av. Reitor Miguel \\ Calmon, s/n - Vale do Canela. \\ CEP 40.110-903 - Salvador/Bahia/Brasil. Telefone: (71) 3283-8773 E- \\ mail: soniagomes3@gmail.com \\ Luan Estrela Souza \\ Graduando em Ciências Contábeis Universidade Federal da Bahia \\ Endereço: Faculdade de Ciências Contábeis- Av. Reitor Miguel \\ Calmon, Vale do Canela, CEP 40.110-903 Salvador/Bahia/Brasil. \\ Telefone: (71) 3283-8773 \\ e-mail: luan estrela souza@hotmail.com
}

\author{
Thayse Santos da Cruz \\ Mestranda em Contabilidade pela Universidade Federal da Bahia \\ Endereço: Faculdade de Ciências Contábeis- Av. Reitor Miguel \\ Calmon, s/n - Vale do Canela, CEP 40.110-903 Salvador/Bahia/Brasil. \\ Telefone: (71) 3283-8773 \\ e-mail: thayse.cruz@hotmail.com \\ Igor Borges Gomes \\ Graduado em Ciências Contábeis Universidade Federal da Bahia \\ Endereço: Faculdade de Ciências Contábeis- Av. Reitor Miguel \\ Calmon, s/n - Vale do Canela, CEP 40.110-903 Salvador/Bahia/Brasil. \\ Telefone: (71) 3283-8773 \\ e-mail: igorn2@hotmail.com
}

\section{RESUMO}

A presente pesquisa teve o objetivo de investigar o nível de conhecimento dos futuros profissionais de contabilidade do estado da Bahia sobre os conceitos básicos apresentados nas normas brasileiras de contabilidade. Para tanto, aplicou-se questionário como instrumento de coleta de dados. Participaram da pesquisa 876 discentes de IES públicas e privadas localizadas na Bahia. Para tabulação e análise dos dados utilizou-se o software Statistical Package for Social Sciences - SPSS ${ }^{\circledR}$ versão 21. Os dados foram tratados de forma individual e descritiva, considerando-se para isso as estatísticas de frequência dos respondentes a cada questão. A investigação constatou que os discentes baianos não apresentam conhecimento satisfatório acerca de conceitos básicos presentes nas normas brasileiras de contabilidade, uma vez que de nove proposições, em apenas três a quantidade de estudantes que respondeu corretamente ao questionário ultrapassou $50 \%$. Os achados evidenciam uma realidade preocupante, pois os conhecimentos averiguados nesta investigação são necessários para a compreensão e aplicação das normas brasileiras de contabilidade. Desta forma, sugere-se que trabalhos futuros investiguem quais as causas desta falta

${ }_{1}^{1}$ Artigo recebido em 29.09.2014. Revisado pelos pares em 02.06.2015 (blind review). Ajustado e Aceito para publicação em 07.07.2015. Recomendado para publicação por José Ribamar Marques de Carvalho (Editor Científico). Publicado em 05.08.2015. Organização responsável UACC/CCJS/UFCG. 
de domínio conceitual. Quanto à limitação deste estudo, existe o fato do mesmo restringir-se à amostra pesquisada, não permitindo generalizações. Desta forma, sugere-se também que sejam realizados estudos com estudantes de Ciências Contábeis de outros estados do país, a fim de se comparar seus achados com os resultados desta pesquisa.

Palavras-chave: Nível de Conhecimento dos discentes. Ensino da Contabilidade. Normas Brasileiras de Contabilidade.

\begin{abstract}
This research aimed to investigate the level of knowledge of the accounting future professionals in state of Bahia on the basic concepts presented in Brazilian accounting standards. Therefore, we applied questionnaire as a data collection instrument. The participants were 876 students from public and private institutions located in Bahia. For tabulation and analysis was used the software Statistical Package for Social Sciences - SPSS version 21. The data were treated individually and descriptive, considering the statistics of frequency of respondents to each question. The research found that Bahia students do not have adequate knowledge about basic concepts presented in Brazilian accounting standards, of the nine propositions in just three the number of students who correctly answered the questionnaire exceeded $50 \%$. The findings show a worrying reality, because the knowledge investigated in this research is necessary for the understanding and application of Brazilian accounting standards. Thus, it is suggested further work investigating what causes this lack of conceptual domain. Limitation of this study is the fact the same be limited to the sample studied, not allowing generalizations. In this way it also suggests studies with students from Accounting of other states in order to compare their findings with the results of this research.
\end{abstract}

Key words: Knowledge level of students. Teaching of Accounting. Brazilian Accounting Standards.

\title{
RESUMEN
}

Esta investigación tuvo como objetivo investigar el nivel de conocimiento de los futuros de profesionales de contabilidad en el estado de Bahía sobre los conceptos básicos presentados en las normas contables brasileñas. Por lo tanto, se aplicó cuestionario como instrumento de recolección de datos. Los participantes fueron 876 estudiantes de instituciones públicas y privadas ubicadas en Bahía. Para la tabulación y análisis fue utilizado el software Paquete Estadístico para las Ciencias Sociales - SPSS versión 21. Los datos fueron tratados de forma individual y descriptiva, teniendo en cuenta las estadísticas de frecuencia de los encuestados a cada pregunta. La investigación encontró que los estudiantes de Bahía no tienen un conocimiento adecuado sobre los conceptos básicos presentados en las normas contables brasileñas, ya que nueve proposiciones en sólo tres el número de estudiantes que respondió correctamente el cuestionario superó el 50\%. Los resultados muestran una realidad preocupante, ya que el conocimiento investigado en esta investigación son necesarios para la comprensión y aplicación de las normas contables brasileñas. Por lo tanto, se sugiere que la labor de investigar las causas de esta falta de dominio conceptual. En cuanto a la Limitación de este estudio esta el hecho de que el mismo se limita a la muestra estudiada, no permitiendo generalizaciones. Por lo tanto, también sugieren que los estudios con estudiantes de Contabilidad de otros estados con el fin de comparar sus resultados con los resultados de esta investigación.

Palabras clave: nivel de conocimientos de los estudiantes. Enseñanza de la Contabilidad. Las normas contables brasileñas

\section{INTRODUÇÃO}

O padrão da International Financial Reporting Standards (IFRS) representa uma das maiores mudanças que ocorreram na contabilidade brasileira desde a publicação da Lei 6.404, no ano de 1976. O processo de convergência das normas brasileiras de contabilidade às IFRS teve início em 1990, quando a Comissão de Valores Mobiliários (CVM), através da criação de um grupo de trabalho, denominado Comissão 
Consultiva para Assuntos Contábeis, preparou o primeiro esboço da revisão normativa pretendida, que posteriormente serviu de base para o Projeto de Lei 3.741/2000. Esse projeto transformou-se na Lei 11.638/07, sancionada pelo presidente Luís Inácio Lula da Silva em 28/12/2007, ajustada posteriormente pela Lei 11.941/09.

O processo de convergência se acelerou quando o Comitê de Pronunciamentos Contábeis (CPC) começou a traduzir as IFRS, adequando-as à realidade brasileira. Esse Comitê foi criado com o objetivo de estudar, preparar e emitir pronunciamentos técnicos sobre procedimentos de contabilidade e a divulgação de informações dessa natureza, para permitir a emissão de normas pela entidade reguladora brasileira, visando à centralização e uniformização do seu processo de produção, levando sempre em conta a convergência da contabilidade brasileira aos padrões internacionais. (CPC, 2014).

Os pronunciamentos do CPC são referendados pelo Conselho Federal de Contabilidade, transformando-os em Normas Brasileiras de Contabilidade (NBC). Essas normas constituem-se num conjunto de regras e procedimentos de conduta que devem ser observados como requisitos para o exercício da profissão contábil, bem como os conceitos doutrinários, princípios, estrutura técnica e procedimentos a serem aplicados na realização dos trabalhos previstos nas normas aprovadas por resoluções emitidas pelo CFC.

Devido ao processo de convergência das normas contábeis brasileiras aos padrões da International Financial Reporting Standard (IFRS), as instituições de ensino superior e os docentes têm o desafio de ofertar aos estudantes um curso em conformidade com as normas brasileiras de contabilidade, visto que as mesmas estão alinhadas as IFRS. Diante deste contexto, levantou-se o seguinte problema de pesquisa: os discentes do curso de graduação de Ciências Contábeis no estado da Bahia apresentam nível de conhecimento satisfatório sobre os conceitos básicos presentes nas normas brasileiras de contabilidade?

Assim, esta pesquisa tem por objetivo investigar o nível de conhecimento dos futuros profissionais de contabilidade do estado da Bahia sobre os conceitos básicos apresentados nas normas brasileiras de contabilidade.

As pesquisas recentes sobre este assunto realizadas no Brasil buscaram analisar o nível de adequação do currículo das IES à proposta do ISAR/UNCTAD/ONU e captar a percepção dos docentes e discentes sobre o processo de convergência às normas internacionais. (CZENAST; CUNHA; DOMINGUES, 2009; REIS, NOGUEIRA E BIN, 2010; FERNANDES et al. 2010; SANTOS, DOMINGUES E RIBEIRO, 2011; CAMPOS E LEMES , 2011; PEREIRA, NIYAMA E FREIRE, 2012; SEGANTINI et al. 2013; KUHN, 2013).

A presente investigação busca aferir de forma objetiva o nível de conhecimento dos futuros profissionais de contabilidade, com a finalidade de contribuir para avaliar 
o quanto os estudantes do curso de Ciências Contábeis do estado da Bahia compreendem conceitos básicos abordados pelas normas brasileiras de contabilidade. Sob esta perspectiva, considera-se relevante identificar se os futuros profissionais estão sendo devidamente preparados para as demandas desafiadoras do contexto atual, além disso, os achados poderão contribuir para fomentar discussões sobre o delineamento do Projeto Político Pedagógico das IES investigadas.

\section{REFERENCIAL TEÓRICO}

Este referencial teórico apresenta um breve histórico do processo de convergência das normas brasileiras de contabilidade às IFRS. De modo complementar, apresentam-se pesquisas empíricas sobre a temática do ensino da contabilidade no contexto do processo de convergência.

\section{1 O PROCESSO DE CONVERGÊNCIA DO BRASIL ÀS IFRS}

O processo de convergência das Normas Brasileiras de Contabilidade às IFRS (International Financial Reporting Standard) teve início em 1990, quando a Comissão de Valores Mobiliários (CVM), através da criação de um grupo de trabalho, denominado Comissão Consultiva para Assuntos Contábeis, que preparou o primeiro esboço da revisão normativa pretendida, que posteriormente serviu de base para o Projeto de Lei 3.741/2000. Esse projeto transformou-se na Lei 11.638/07, que fora, ajustada posteriormente pela Lei 11.941/09.

A lei 11.638/07 é considerada um marco legal de suma relevância para as práticas contábeis, pois inseriu o Brasil ao processo de internacionalização, determinando a harmonização contábil com as IFRS (SANTOS E CALIXTO, 2010). Neste contexto, deve-se destacar que antes da lei 11.638/07, houve a criação pelo Conselho Federal de Contabilidade (CFC) do Comitê de Pronunciamentos Contábeis (CPC) através da Resolução $\mathrm{n}^{\mathrm{o}}$ 1.055/05. Este é resultado da união das entidades Associação Brasileira das Companhias Abertas (ABRASCA), Associação dos Analistas e Profissionais do Mercado de Capitais, Bolsa de Valores, Mercadorias e Futuros (BM\&F Bovespa), Conselho Federal de Contabilidade (CFC), Instituto dos Auditores Independentes do Brasil (IBRACON) e (FIPECAFI) Fundação Instituto de Pesquisas Contábeis, Atuariais e Financeiras (CPC, 2014).

A criação do CPC ocorreu por necessidade de convergência internacional das normas brasileiras, da centralização na emissão desse tipo de norma e de representação e processo democrático na produção das informações (COSTA et. al 2013). Nesse sentido, as atividades do referido comitê dão origem a pronunciamentos técnicos, orientações técnicas e interpretações, sendo que os pronunciamentos técnicos 
são obrigatoriamente submetidos a audiências públicas, a fim de se garantir o máximo de transparência e participação das diversas partes interessadas no processo de adoção das normas internacionais (LIMA, 2010).

Apesar dos esforços de diversas entidades para a convergência brasileira às normas internacionais, os pronunciamentos emanados pelo CPC não possuem caráter normativo. Portanto, conforme relata Pereira (2011), havia a necessidade de regulamentação do processo de convergência corrente, o que ocorreu a partir da Lei no 11.638/07. Neste cenário, a Comissão de Valores Mobiliários, por meio da Instrução no 457/07, decretou que até o fim de 2010 as sociedades anônimas de capital aberto, bem como aquelas, mesmo de capital fechado, mas de grande porte, elaborassem e apresentassem suas demonstrações contábeis em convergência às normas internacionais (LIMA, 2011; OLIVEIRA E LEMES, 2011; COSTA et. al., 2013).

Outro marco importante neste processo ocorreu quando foi promulgada a Lei 11.941/09. Esta lei instituiu o regime tributário de transição, bem como outras providências. Dessa forma, aplicou-se a neutralidade fiscal às normas emitidas pelos órgãos reguladores, com o propósito de permitir o alinhamento da legislação específica com os padrões internacionais de contabilidade.

Lima (2010) salienta que a implementação dos pronunciamentos ocorreu em duas etapas: a primeira, a partir de 2008, com os pronunciamentos $\mathrm{n}^{\circ} 01$ até 14; e a segunda, a partir de 2010, com os pronunciamentos no 15 em diante. Atualmente existem 46 pronunciamentos (CPC, 2014). Nessa linha, Fiorentin et. al. (2011) destacam que as normas internacionais às quais o Brasil tem convergido induzem aos países que elas adotam a harmonizarem-se às mesmas, ou seja, de serem os mais próximos possíveis ao seu conteúdo, mas respeitando características locais inerentes. Sob esta perspectiva, Niyama, J. K. (2005, p.15) defende que os valores culturais, a tradição histórica, as estruturas políticas, econômicas e sociais influenciam as práticas contábeis de uma nação e, logo, o avanço das mesmas pode estar vinculado ao nível de desenvolvimento econômico de cada país.

Por isso, o processo de convergência se justifica, uma vez que o mundo dos negócios passou a demandar informação contábil única, confiável e comparável, que reduzisse os custos e incertezas ao analisar informações contábeis oriundas de países diferentes. Neste sentido, o International Accounting Standards Board (IASB) atua como órgão emissor de normas internacionais, as IFRS, às quais diversos países, inclusive $o$ Brasil tem convergido suas normas contábeis.

\subsection{O ENSINO DA CONTABILIDADE E O PROCESSO DE CONVERGÊNCIA}


Pesquisas empíricas apontam que, em consequência do processo de convergência às normas internacionais, as instituições de ensino superior e os docentes têm o desafio de ofertar para os futuros profissionais um curso alinhado aos padrões internacionais (CZENAST; CUNHA; DOMINGUES, 2009; REIS, NOGUEIRA E BIN, 2010; FERNANDES et al. 2011; SANTOS, DOMINGUES E RIBEIRO, 2011; CAMPOS E LEMES , 2011; LIMA FILHO E BRUNI, 2012; PEREIRA, NIYAMA E FREIRE, 2012; SEGANTINI et al. 2013; KUHN, 2013).

Sob esta perspectiva, a investigação realizada por Reis, Nogueira e Bin (2010) buscou compreender a percepção dos discentes e docentes de Ciências Contábeis, em relação ao processo de convergência. Os achados apontam que a maioria dos discentes tem conhecimento da existência do processo, no entanto, acreditam equivocadamente que as transformações estão mais relacionadas a questões formais, como a nomenclatura dos grupos patrimoniais, do que a aspectos conceituais. Os docentes, por sua vez, embora tenham conhecimento a respeito das mudanças, ainda apresentam certa resistência em promover as alterações conceituais necessárias, que promoverão a transposição da prática contábil nacional para as normas internacionais. Verificou-se que uma parcela significativa ainda não tem conhecimento de conteúdos essenciais.

Nessa linha, Oliveira, Jacone e Almeida (2012) realizaram um estudo a fim de verificar a percepção dos estudantes de Ciências Contábeis de duas universidades acerca do processo de convergência às normas internacionais, a partir de uma amostra de 48 discentes cursando o $8^{\circ}$ semestre. Os resultados encontrados pelos pesquisadores apontaram que os estudantes apresentam um bom conhecimento do processo de convergências das normas contábeis.

Ainda no tocante à percepção dos estudantes acerca do processo de introdução das normas internacionais de contabilidade, Armond, Avelino e Nascimento (2012) averiguaram tal aspecto em estudantes de IES de Minas Gerais. Além disso, os autores investigaram o perfil dos estudantes, bem como a existência de disciplina acerca da temática contabilidade internacional nas universidades pesquisadas. Nesse sentido, em apenas uma instituição o referido componente curricular ou similar é oferecido, de forma a notar-se a falta de profundidade na oferta desta disciplina, e consequentemente, da percepção dos estudantes sobre as referidas normas. Apesar disso, os autores constataram que a maioria dos discentes investigados sabe da importância do conhecimento acerca da temática para o sucesso profissional.

Lima Filho e Bruni (2012) se propuseram a investigar a percepção acerca de conceitos básicos tratados na disciplina Teoria da Contabilidade, tais como os de ativo, passivo, receita e despesa, por parte dos estudantes de Ciências Contábeis de IES situadas em Salvador, na Bahia. Para tanto, os pesquisadores utilizaram-se da aplicação de questionário a 591 discentes e buscaram verificar possíveis relações entre 
os resultados encontrados e o tipo de IES e a titulação do professor da referida disciplina. Dessa forma, os resultados indicaram que os estudantes, de maneira geral, possuem conhecimentos pouco sedimentados acerca dos conceitos averiguados, bem como se verificou a existência de relação entre o desempenho dos estudantes no questionário com o tipo de IES e com a titulação do professor da disciplina, de forma que os discentes de IES pública e que foram alunos de professores de maior titulação tiveram melhor desempenho.

Partindo do pressuposto de que as Normas Brasileiras de Contabilidade trazem uma necessidade de julgamento e tomada de decisão por parte dos profissionais, Maia (2012) dedicou-se a investigar como tais eventos são abordados nas universidades aos discentes. Para tanto, o autor buscou verificar se os estudantes de Ciências Contábeis de três universidades do Brasil estavam aptos para absorver as demandas ensejadas pelas normas internacionais de contabilidade a partir do que para eles é exposto em sala de aula. Os resultados obtidos apontaram que a abordagem das normas internacionais dadas em sala de aula, não está direcionada para o julgamento e tomada de decisão e sim para a simples memorização.

Utilizando-se da mesma perspectiva do estudo anterior, de que as normas brasileiras de contabilidade para serem compreendidas e aplicadas exigem a capacidade de tomada de decisão e julgamento por parte do contador, Nascimento, Nossa e Balassiano (2013) propuseram-se a investigar se o analfabetismo funcional é um fenômeno relevante como possível entrave ao desenvolvimento dessas capacidades pelos estudantes. A referida investigação ocorreu com discentes concluintes do curso de Ciências Contábeis no Espírito Santo, a partir da utilização de questionário com questões originadas do National Assessment of Adult Literacy - NAAL. Nesse sentido, os achados da investigação indicaram que, de fato, uma parte significativa dos estudantes apresenta analfabetismo funcional, o que constitui um entrave à assimilação e aplicação do exposto nas normas brasileiras de contabilidade.

O estudo realizado por Fernandes et al. (2011), com 190 professores que lecionam nos cursos de graduação em Ciências Contábeis de todo o Brasil, constatou que a maioria dos professores se considera preparada para lecionar nesta nova realidade, embora acreditem que as instituições educacionais brasileiras não estão.

No entanto, a investigação realizada por Kuhn (2013), que avaliou o nível de conhecimento dos docentes de graduação em ciências contábeis da grande Goiânia acerca das normas brasileiras de contabilidade, constatou que o mesmo é baixo, revelando que os docentes não estão aptos para lecionar em conformidade com as IFRS.

A pesquisa conduzida por Dorman (2012) com 66 professores em Rochester/Nova Iorque obteve resultados semelhantes. Verificou-se que os docentes em geral não estão capacitados o suficiente para ensinar conforme as Normas 
Internacionais de Relato Financeiro. Verificou-se também que as instituições de ensino, tanto públicas quanto privadas, não estavam preparadas para ensinar IFRS.

Santos e Quilliam (2013) realizaram entrevistas com 16 docentes na Flórida/ Estados Unidos com o propósito de verificar a preparação individual e institucional para implementação das IFRS nos currículos. Os resultados indicaram que a comunidade acadêmica ainda não está pronta para a implantação do processo de convergência às IFRS.

\section{PROCEDIMENTOS METODOLÓGICOS}

O presente estudo teve o objetivo de investigar o nível de conhecimento dos futuros profissionais de contabilidade do estado da Bahia sobre os conceitos básicos apresentados nas Normas Brasileiras de Contabilidade. Para a consecução deste propósito, aplicou-se o questionário como instrumento de coleta de dados a 876 discentes de IES públicas e privadas localizadas no estado da Bahia durante o ano de 2014. A caracterização da amostra por tipo de instituição de ensino e semestre em curso pode ser verificada nas tabelas 01 e 02.

Tabela 01: Caracterização da amostra quanto ao tipo de instituição

\begin{tabular}{|c|c|c|c|}
\hline & Frequência & Percentual & $\begin{array}{c}\text { Percentual } \\
\text { Válido }\end{array}$ \\
\hline Pública & 325 & 37,1 & 37,4 \\
\hline Privada & 543 & 62,0 & 62,6 \\
\hline Total & 868 & 99,1 & 100 \\
\hline Erro & 8 & 0,9 & \\
\hline Total & 876 & 100 & \\
\hline \multicolumn{4}{|c|}{ Fonte: Dados da Pesquisa } \\
\hline bela 02: Caracter & ร̌ão da amostr & ato ao semest & curso \\
\hline & Frequência & Percentual & $\begin{array}{c}\text { Percentual } \\
\text { Válido }\end{array}$ \\
\hline $1^{\mathrm{o}}$ e $2^{\mathrm{o}}$ semestres & 171 & 19,5 & 20,1 \\
\hline $3^{\circ} 34^{\mathrm{o}}$ semestres & 137 & 15,6 & 16,1 \\
\hline $5^{\circ}$ e $6^{\circ}$ semestres & 262 & 29,9 & 30,8 \\
\hline $7^{\circ}$ e $8^{o}$ semestres & 277 & 31,6 & 32,5 \\
\hline $\begin{array}{l}9 \text { ou mais } \\
\text { semestres }\end{array}$ & 4 & 0,5 & 0,5 \\
\hline Total & 851 & 97,1 & 100 \\
\hline Erro & 25 & 2,9 & \\
\hline Total & 876 & 100 & \\
\hline
\end{tabular}

Fonte: Dados da Pesquisa 
Nota-se, assim, que a amostra selecionada foi composta em sua maioria por estudantes de IES privadas $(62,6 \%)$ cursando os semestres intermediários e finais do curso $(63,3 \%)$. Este último ponto é de especial interesse para esta pesquisa, pois se espera que neste estágio do curso os estudantes já dominem conceitos básicos presentes nas Normas Brasileiras de Contabilidade.

Aplicou-se um questionário, com nove perguntas, para medir o nível de conhecimento dos discentes quanto à compreensão sobre os conceitos básicos presentes nas normas brasileiras de contabilidade. As questões foram elaboradas com base nos conceitos presentes nas seguintes NBC's: Estrutura Conceitual para Elaboração e Divulgação de Relatório Contábil-Financeiro (NBC TG Estrutura Conceitual), Estoques (NBC TG 16 (R1)), Provisões, Passivos Contingentes e Ativos Contingentes (NBC TG 25), Ativo Imobilizado (NBC TG 27 (R1)) e Receitas (NBC TG 30). Cada assertiva poderia ser assinalada com a resposta sim, não ou não sei. A tabulação e análise dos dados obtidos foram realizadas por meio do programa Statistical Package for Social Sciences - SPSS® versão 21, de forma individual e descritiva, considerando-se para isso as estatísticas de frequência dos respondentes a cada questão. O resultado da investigação será apresentado a seguir nas tabelas de 03 a 11.

\section{APRESENTAÇÃO E DISCUSSÃO DOS RESULTADOS}

Os dados abaixo se referem às evidências encontradas na investigação sobre o nível de conhecimento dos futuros profissionais de contabilidade do estado da Bahia acerca dos conceitos básicos apresentados nas Normas Brasileiras de Contabilidade. Os resultados estão apresentados nas tabelas de 03 a 11. Para esta análise foi utilizado o percentual válido das respostas em cada questão, obtido pela exclusão dos participantes que não responderam a questão. Estas omissões estão apresentadas nas tabelas como "erro".

Na tabela 03 são apresentados os percentuais das respostas da questão que verificou o nível de conhecimento dos alunos quanto aos elementos necessários para o reconhecimento de um recurso como ativo. Perguntou-se aos alunos se para classificar um recurso como ativo é necessário ter sua propriedade. Após a emissão das normas internacionais, a propriedade jurídica do recurso, passou a não ser considerada como um dos critérios para o reconhecimento de um ativo, portanto o conceito apresentado na assertiva é defasado.

\begin{tabular}{lccc}
\hline $\begin{array}{l}\text { Tabela 03- P.1: Para se classificar um recurso como ativo é necessário ter sua } \\
\text { propriedade. }\end{array}$ & Frequência & Percentual & \\
\hline & $\begin{array}{c}\text { Percentual } \\
\text { válido }\end{array}$ & $\begin{array}{c}\text { Percentual } \\
\text { acumulado }\end{array}$ \\
\hline
\end{tabular}




\begin{tabular}{cccccc}
\hline \multirow{3}{*}{ Respostas } & Verdadeiro & 382 & 43,6 & 46,0 & 46,0 \\
& Falso & 362 & 41,3 & 43,6 & 89,6 \\
& Não Sei & 87 & 10,0 & 10,4 & 100 \\
\multirow{2}{*}{ Erro } & Total & 831 & 94,9 & 100 & \\
\cline { 3 - 6 } & & 45 & 5,1 & & \\
\hline
\end{tabular}

Fonte: Dados da pesquisa

Nas respostas obtidas a esta questão um total de $43,6 \%$ dos respondentes responderam corretamente à questão proposta. Enquanto que $46 \%$ afirmaram equivocadamente que para a classificação de um recurso como ativo é necessário ter sua propriedade. Dos alunos investigados, 87 respondentes, representando 10,4\%, assinalaram a opção "não sei" para esta questão.

Ainda com relação ao conceito de ativo, mais especificamente ao imobilizado, apresentou-se a seguinte assertiva: ativo imobilizado é o item tangível que corresponde aos direitos que tenham por objeto bens corpóreos, de propriedade da entidade destinados à manutenção das atividades desta ou exercidos com essa finalidade. Na tabela 04 são apresentadas as respostas dadas pelos estudantes à referida assertiva.

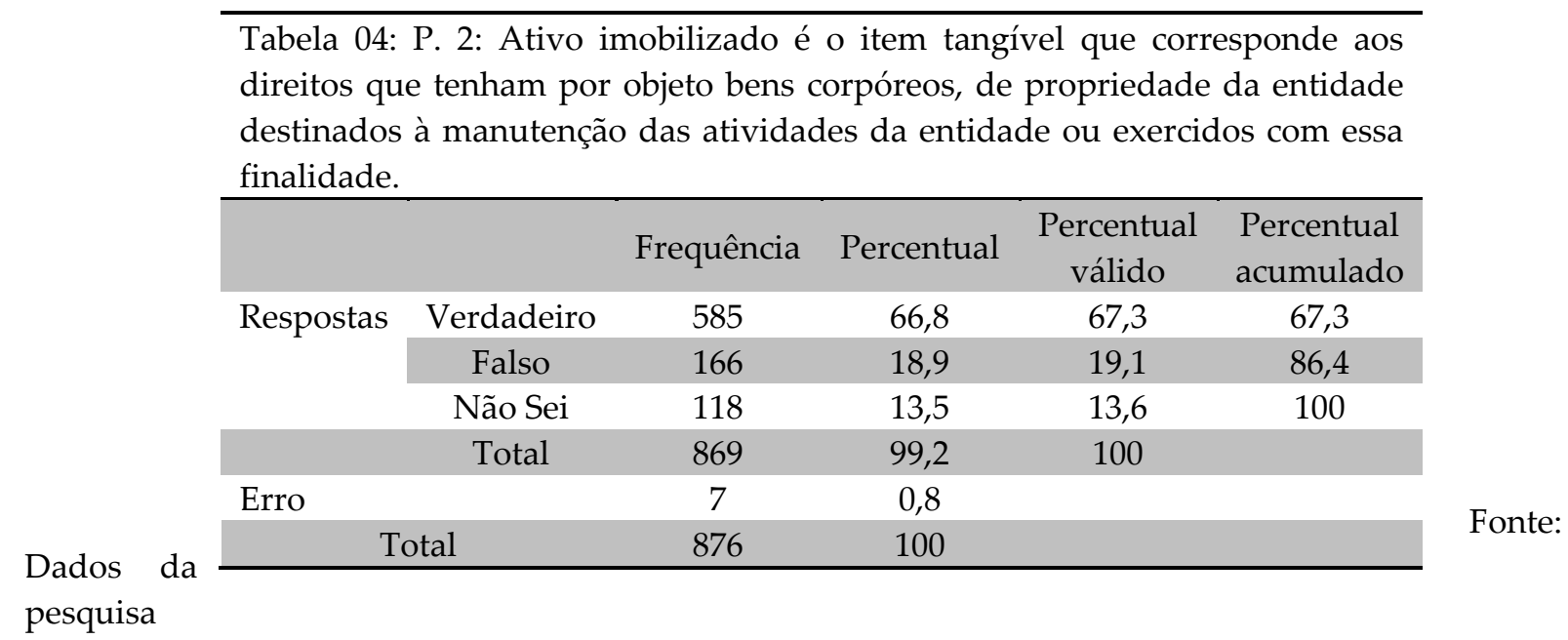

A pesquisa constatou que apenas 166 alunos (19,1\%) responderam corretamente à questão. Enquanto isso, a maioria dos discentes não apresentou domínio sobre o conceito de ativo imobilizado, uma vez que 585 estudantes $(67,3 \%)$ responderam equivocadamente à questão e 118 (13,6\%) assinalaram a opção "não sei". 
Com relação à avaliação de ativos, mais especificamente pelo método do custo histórico, apresentou-se a seguinte assertiva: custo histórico é aquele em que os ativos são registrados pelos montantes pagos em caixa ou equivalentes de caixa ou pelo valor justo dos recursos entregues para adquiri-los na data da aquisição. Os achados encontram-se na tabela 05 .

\begin{tabular}{lccccc}
\hline $\begin{array}{l}\text { Tabela 05 - P.3: Custo histórico é aquele em que os ativos são registrados pelos } \\
\text { montantes pagos em caixa ou equivalentes de caixa ou pelo valor justo dos recursos } \\
\text { entregues para adquiri-los na data da aquisição. }\end{array}$ \\
\hline \multicolumn{7}{c}{ Frequência } & Percentual & $\begin{array}{c}\text { Percentual } \\
\text { válido }\end{array}$ & $\begin{array}{c}\text { Percentual } \\
\text { acumulado }\end{array}$ \\
\multirow{7}{*}{ Respostas } & Verdadeiro & 472 & 53,9 & 55,1 & 55,1 \\
& Falso & 161 & 18,4 & 18,8 & 73,9 \\
& Não Sei & 223 & 25,4 & 26,1 & 100 \\
\multirow{5}{*}{ Erro } & Total & 856 & 97,7 & 100 & \\
\hline
\end{tabular}

Fonte: Dados da pesquisa

Verificou-se que a maioria dos alunos investigados $(55,1 \%)$ respondeu corretamente o quesito. A pesquisa constatou que 161 dos discentes $(18,8 \%)$ consideraram falso o conceito de custo histórico apresentado, o que demonstra a falta de conhecimento dos investigados sobre o assunto. Além disso, 26,1\% dos alunos afirmaram não saber responder à assertiva.

Na tabela 06 são apresentados os percentuais de acerto e erro da questão que verificou o nível de conhecimento dos alunos quanto ao conceito de valor justo. A mensuração a valor justo (fair value) é um assunto advindo do processo de convergência. O conceito de valor justo está presente em diversas NBC's, por isso é de suma relevância que os discentes dominem a temática. Sob esta perspectiva, apresentou-se a seguinte assertiva: valor justo é aquele pelo qual um ativo pode ser trocado ou um passivo liquidado entre partes interessadas, conhecedoras do negócio e independentes entre si, com ausência de fatores que pressionem para a liquidação da transação ou que caracterizem uma transação compulsória. 
independentes entre si, com ausência de fatores que pressionem para a liquidação da transação ou que caracterizem uma transação compulsória.

\begin{tabular}{|c|c|c|c|c|c|c|}
\hline \multirow{7}{*}{ Dados } & & & Frequência & Percentual & $\begin{array}{l}\text { Percentual } \\
\text { válido }\end{array}$ & $\begin{array}{l}\text { Percentual } \\
\text { acumulado }\end{array}$ \\
\hline & \multirow{4}{*}{ Respostas } & Verdadeiro & 327 & 37,3 & 37,8 & 37,8 \\
\hline & & Falso & 252 & 28,8 & 29,2 & 67 \\
\hline & & Não Sei & 285 & 32,5 & 33,0 & 100 \\
\hline & & Total & 864 & 98,6 & 100 & \\
\hline & Erro & & 12 & 1,4 & & \\
\hline & \multicolumn{2}{|c|}{ Total } & 876 & 100 & & \\
\hline
\end{tabular}

A pesquisa constatou que apenas 327 alunos $(37,8 \%)$ responderam corretamente a questão. Enquanto que a maioria dos alunos não apresentou domínio sobre o conceito de valor justo, uma vez que $29,2 \%$ dos discentes não acertaram a questão e 33\% dos respondentes afirmaram não saber responder à assertiva. Destacase que esta foi a questão que apresentou maior proporção de respostas "não sei", 33\% do percentual válido. Isto pode estar relacionado ao fato de a mensuração a valor justo ser um conceito advindo do processo de convergência.

Em se tratando dos critérios de custeio dos estoques, perguntou-se aos estudantes se a entidade deve usar sempre o mesmo critério de custeio para todos os seus estoques. Os resultados encontram-se na tabela 07.

\begin{tabular}{|c|c|c|c|c|c|}
\hline \multicolumn{6}{|c|}{$\begin{array}{l}\text { Tabela 07- P.5: A entidade deve usar o mesmo critério de custeio para todos } \\
\text { os seus estoques. }\end{array}$} \\
\hline & & Frequência & Percentual & $\begin{array}{l}\text { Percentual } \\
\text { válido }\end{array}$ & $\begin{array}{l}\text { Percentual } \\
\text { acumulado }\end{array}$ \\
\hline \multirow[t]{4}{*}{ Respostas } & Verdadeiro & 267 & 30,5 & 32,3 & 32,3 \\
\hline & Falso & 464 & 53,0 & 56,1 & 88,4 \\
\hline & Não Sei & 96 & 10,9 & 11,6 & 100 \\
\hline & Total & 827 & 94,4 & 100 & \\
\hline \multirow{2}{*}{\multicolumn{2}{|c|}{ Erro }} & 49 & 5,6 & & \\
\hline & & 876 & 100 & & \\
\hline
\end{tabular}

Fonte: Dados da pesquisa

Verificou-se que a maioria dos discentes pesquisados, $464(56,1 \%)$ respondeu corretamente ao quesito. A pesquisa constatou que 267 alunos $(32,3 \%)$ responderam equivocadamente à questão proposta. Enquanto isso, 96 dos discentes $(11,6 \%)$ assinalaram a opção "não sei".

No que tange à identificação de itens patrimoniais, perguntou-se se itens como depreciação e redução ao valor recuperável de ativos são ajustes dos valores contábeis de ativos, enquanto que provisão é um passivo de prazo e/ou valor incertos. Na tabela 08 são apresentados os percentuais das respostas desta questão. 


\begin{tabular}{|c|c|c|c|c|c|}
\hline \multicolumn{6}{|c|}{$\begin{array}{l}\text { Tabela 08: P. 6: Itens como depreciação e redução ao valor recuperável de ativos } \\
\text { são ajustes dos valores contábeis de ativos, enquanto que provisão é um passivo de } \\
\text { prazo e/ou valor incertos. }\end{array}$} \\
\hline & & Frequência & Percentual & $\begin{array}{l}\text { Percentual } \\
\text { válido }\end{array}$ & $\begin{array}{l}\text { Percentual } \\
\text { acumulado }\end{array}$ \\
\hline \multirow{4}{*}{ Respostas } & Verdadeiro & 481 & 54,9 & 55,4 & 55,4 \\
\hline & Falso & 238 & 27,2 & 27,4 & 82,7 \\
\hline & Não Sei & 150 & 17,1 & 17,2 & 100 \\
\hline & Total & 869 & 99,2 & 100 & \\
\hline \multirow[t]{2}{*}{ Erro } & & 7 & 0,8 & & \\
\hline & & 876 & 100 & & \\
\hline
\end{tabular}

Fonte: Dados da Pesquisa

Os achados indicam que a maioria dos alunos investigados, 481 , ou $55,4 \%$, respondeu corretamente ao quesito. Verificou-se que 238 discentes $(27,4 \%)$ responderam de forma equivocada esta questão. Outros 150 alunos, ou 17,2\% do percentual válido assinalaram a opção "não sei".

Com relação ao conceito de passivo, apresentou-se a seguinte assertiva: é uma obrigação presente da entidade, derivada de eventos que irão ocorrer, cuja liquidação se espera que resulte em saída de recursos da entidade capazes de gerar benefícios econômicos. Na tabela 09 estão apresentadas as repostas dadas pelos alunos com relação a esta afirmação.

\begin{tabular}{|c|c|c|c|c|c|}
\hline \multicolumn{6}{|c|}{$\begin{array}{l}\text { Tabela } 09 \text { - P.7: Passivo é uma obrigação presente da entidade, derivada de eventos } \\
\text { que irão ocorrer, cuja liquidação se espera que resulte em saída de recursos da } \\
\text { entidade capazes de gerar benefícios econômicos. }\end{array}$} \\
\hline & & Frequência & Percentual & $\begin{array}{l}\text { Percentual } \\
\text { válido }\end{array}$ & $\begin{array}{l}\text { Percentual } \\
\text { acumulado }\end{array}$ \\
\hline \multirow{4}{*}{ Respostas } & Verdadeiro & 518 & 59,1 & 61,2 & 61,2 \\
\hline & Falso & 261 & 29,8 & 30,8 & 92,0 \\
\hline & Não Sei & 68 & 7,8 & 8,0 & 100 \\
\hline & Total & 847 & 96,7 & 100 & \\
\hline \multirow[t]{2}{*}{ Erro } & & 29 & 3,3 & & \\
\hline & & 876 & 100 & & \\
\hline
\end{tabular}

Fonte: Dados da pesquisa

A pesquisa constatou que apenas 261 alunos (30,8\%) responderam de forma correta a questão. Os resultados indicaram ainda que a maioria dos respondentes, ou seja, 586 alunos $(69,2 \%)$, não possuem conhecimento sobre o conceito de passivo, uma vez que 518 alunos (61,2\%) não acertaram à questão e 68 discentes (8\%) afirmaram que não sabiam responder esta assertiva. 
Quanto aos critérios de reconhecimento de receita, apresentou-se a seguinte proposição: um credor da entidade renunciou a seus direitos, eliminando a necessidade da mesma de liquidar certa obrigação. Como este evento levou a uma diminuição de passivos, ele dá origem a uma receita. Na tabela 10 são apresentados os percentuais das respostas a esta questão.

\begin{tabular}{|c|c|c|c|c|c|}
\hline \multicolumn{6}{|c|}{$\begin{array}{l}\text { Tabela 10- P.8: Um credor da entidade renunciou a seus direitos, eliminando a } \\
\text { necessidade da mesma de liquidar certa obrigação. Como este evento levou a uma } \\
\text { diminuição de passivos, ele dá origem a uma receita. }\end{array}$} \\
\hline & & Frequência & Percentual & $\begin{array}{l}\text { Percentual } \\
\text { válido }\end{array}$ & $\begin{array}{l}\text { Percentual } \\
\text { acumulado }\end{array}$ \\
\hline \multirow{4}{*}{ Respostas } & Verdadeiro & 317 & 36,2 & 36,9 & 36,9 \\
\hline & Falso & 421 & 48,1 & 49,0 & 85,8 \\
\hline & Não Sei & 122 & 13,9 & 14,1 & 100 \\
\hline & Total & 860 & 98,2 & 100 & \\
\hline \multirow[t]{2}{*}{ Erro } & & 16 & 1,8 & & \\
\hline & tal & 876 & 100 & & \\
\hline
\end{tabular}

Fonte: Dados da pesquisa

Os resultados indicaram que a maioria dos discentes $(63,2 \%)$ não possui conhecimento sobre o assunto, uma vez que 421 discentes (49\%) erraram a assertiva e $14,1 \%$ ou 122 alunos, afirmaram que não sabiam responder a questão. Dessa forma, constatou-se que apenas 317 discentes $(36,9 \%)$ responderam corretamente a questão apresentada.

Ainda com relação aos critérios de reconhecimento de uma receita, apresentouse a seguinte proposição: a receita só deve ser reconhecida quando for provável que os benefícios econômicos associados à transação fluirão para a entidade. Na tabela 11 estão apresentadas as repostas dadas pelos alunos com relação a esta afirmação.

\begin{tabular}{|c|c|c|c|c|c|}
\hline & & Frequência & Percentual & $\begin{array}{l}\text { Percentual } \\
\text { válido }\end{array}$ & $\begin{array}{l}\text { Percentual } \\
\text { acumulado }\end{array}$ \\
\hline \multirow{4}{*}{ Respostas } & Verdadeiro & 369 & 42,1 & 42,6 & 42,6 \\
\hline & Falso & 363 & 41,4 & 41,9 & 84,5 \\
\hline & Não Sei & 134 & 15,4 & 15,5 & 100 \\
\hline & Total & 866 & 98,9 & 100 & \\
\hline \multirow[t]{2}{*}{ Erro } & & 10 & 1,1 & & \\
\hline & tal & 876 & 100 & & \\
\hline
\end{tabular}

Fonte: Dados da pesquisa

A pesquisa constatou que a maioria dos alunos pesquisados demonstrou não possuir conhecimento sobre o assunto, uma vez que 363 estudantes $(41,4 \%)$ 
consideraram a assertiva falsa, e 134 (15,3\%) assinalaram a opção "não sei". Apenas $42,1 \%$, correspondente a 369 alunos, respondeu corretamente esta questão.

Os resultados desta pesquisa indicaram que a maioria dos futuros profissionais de contabilidade do estado da Bahia não apresenta nível de conhecimento satisfatório acerca dos conceitos básicos presentes nas normas brasileiras de contabilidade, uma vez que das nove assertivas, em apenas três delas a quantidade de estudantes que respondeu corretamente ao questionário ultrapassou $50 \%$. Os alunos atingiram percentuais de acertos maiores nos itens referentes ao custeio de estoques $(56,10 \%)$; depreciação, redução ao valor recuperável de ativos e provisão $(55,40 \%)$ e conceito de custo histórico $(55,10 \%)$.

\section{CONSIDERAÇÕES FINAIS}

Esta pesquisa teve o propósito de analisar o nível de conhecimento dos futuros profissionais de contabilidade do estado da Bahia sobre conceitos básicos apresentados nas normas brasileiras de contabilidade. Para tanto, aplicou-se o questionário como instrumento de coleta de dados a 876 discentes de IES públicas e privadas localizadas na Bahia. A tabulação e análise dos dados obtidos foram realizadas por meio do programa Statistical Package for Social Sciences - SPSS® versão 21, de forma individual e descritiva, considerando-se para isso as estatísticas de frequência das respostas a cada questão.

A pesquisa constatou que a maioria dos estudantes investigados não apresenta nível de conhecimento satisfatório acerca dos conceitos básicos presentes nas normas brasileiras de contabilidade. Os achados demonstraram que, de nove proposições, em apenas três, equivalente a 33,33\%, a quantidade de estudantes que respondeu corretamente ao questionário ultrapassou $50 \%$. Os resultados indicaram que os alunos atingiram percentuais de acertos maiores nos itens referentes ao custeio de estoques (56,10\%), depreciação, redução ao valor recuperável de ativos e provisão $(55,40 \%)$ e conceito de custo histórico $(55,10 \%)$.

Por meio dos resultados deste estudo, espera-se fomentar discussões para aperfeiçoar o processo de ensino-aprendizagem com a finalidade de melhorar o aprendizado dos futuros profissionais de contabilidade. As evidências obtidas demonstram que estes não estão sendo devidamente preparados para as demandas desafiadoras do contexto atual, pois não dominam conceitos que são fundamentais para o entendimento e aplicação das normas brasileiras de contabilidade.

Portanto, sugere-se que trabalhos futuros investiguem as causas de tais resultados, a fim de se verificar se os achados desta pesquisa tem relação com os do estudo de Fernandes et al. (2011), que constatou a falta de preparo das instituições de ensino superior, assim como os obtidos por Reis, Nogueira e Bin, (2010) e Kuhn (2013), 
que identificaram a falta de capacitação dos docentes para lecionarem em conformidade com as normas brasileiras de contabilidade após o processo de convergência às IFRS.

Quanto às limitações deste estudo, tem-se o fato do mesmo ser restrito à amostra pesquisada, o que não permite que se façam generalizações. Desta forma, sugere-se também que sejam realizadas pesquisas em IES de outros estados do país, a fim de se comparar seus achados com os resultados desta pesquisa.

\section{REFERÊNCIAS}

ARMOND, M. C.; AVELINO, B; C.; NASCIMENTO, E. M. A percepção de estudantes de cursos de Ciências Contábeis em relação ao ensino da disciplina contabilidade internacional à adoção das normas internacionais no Brasil. In: XI CONGRESSO USP INICIAÇÃO CIENTÍFICA, São Paulo, SP, Brasil.Anais... São Paulo/SP: 21 a 23 de julho de 2014.

BRASIL. Lei no 11.638, de 28 de dezembro de 2007. Disponível em: $<$ http://www.planalto.gov.br/ccivil 03/Ato2007-2010/2009/Lei/L11941.htm>. Acesso em: 8 de jan. 2014.

CAMPOS, L.C; LEMES, S. Análise comparativa entre o Currículo Mundial proposto pela ONU/UNCTAD/ISAR e as Universidades Federais da Região Sudeste.In: III ENCONTRO DE ENSINO E PESQUISA EM ADMINISTRAÇÃO E CONTABILIDADE DA ANPAD, João Pessoa/PB. Anais... João Pessoa/PB:20 a 22 de novembro de 2011.

COMITÊ DE PRONUNCIAMENTOS CONTÁBEIS. Disponível em: <http://www.cpc.org.br/index.php>. Acesso em: 24 jan. 2014.

COSTA, Leonardo da; NASCIMENTO, s.; LAGIOIA, U.; ARAÚJO, Juliana de; LEMOS, L. Uma Investigação acerca das Percepções dos Discentes do Brasil e de Portugal sobre a Convergência da Contabilidade aos Padrões Internacionais. Revista de Contabilidade UFBA, Salvador, v. 7, n. 1, p. 55-68, Janeiro 2013.

CZESNAT, A. F. O; CUNHA, J. V. A; DOMINGUES, M. J. C. S. S. Uma análise comparativa entre os currículos dos cursos de ciências contábeis das universidades do Estado de Santa Catarina listadas no MEC com o currículo internacional proposto pela UNCTAC/ONU/ISAR. Revista Gestão \& Regionalidade, vol. 25, nº. 75, set./dez. 2009.

DORMAN, A. IFRS at Rochester-Area Institutions: Are Professors Prepared to Teach?. Senior Honors Theses, 2012. 
FERNANDES, B. V. R. et al. Análise da percepção dos docentes dos cursos de graduação em Ciências Contábeis do Brasil quanto ao processo de convergência às normas internacionais de contabilidade aplicadas no Brasil. Revista Contabilidade e Controladoria, Curitiba, v. 3, n. 3, set./dez. 2011.

FIORENTIN, M.; JÚNIOR, R. M. M.; VARELA, S. P.; HEIN. N. Adoção das normas internacionais de contabilidade por empresas brasileiras: o setor de atuação importa? In:XIV SEMINÁRIOS DE ADMINISTRAÇÃO, São Paulo/SP. Anais... São Paulo/SP: 13 e 14 de outubro de 2011.

FREIRE, F. S.; NIYAMA, J. K.; PEREIRA, E.M. Convergência das normas internacionais de contabilidade: uma análise a luz das teorias da educação de Paulo Freire e Libaneo nas Instituições de ensino do Distrito Federal. In: XII CONGRESSO USP DE CONTROLADORIA E CONTABILIDADE, São Paulo/SP. Anais... São Paulo/SP: 26 e 27 de julho de 2012.

INTERNATIONAL FINANCIAL REPORTING STANDARDS. Disponível em: $<$ http://www.ifrs.org/Pages/default.aspx>. Acesso em: 15 jan.2014.

LIMA FILHO, R. N.; BRUNI, A. L. Percepção dos graduandos em Ciências Contábeis de Salvador (BA) sobre os conceitos relevantes da Teoria da Contabilidade. Revista de Educação e Pesquisa em Contabilidade, Brasília, vol. 6, n. 2, abr.jun. 2012, pp. 187203.

LIMA, J. B. N. de. Relevância da Informação Contábil e o Processo de Convergência para as normas IFRS no Brasil. 2010. 244f. Tese (Doutorado em Ciências Contábeis)Universidade de São Paulo- USP, São Paulo, 2010.

MAIA, K. L. C. O ensino de julgamento e tomada de decisão nos cursos de graduação em Ciências Contábeis no Brasil.2012. 133f. Dissertação (Mestrado executivo em gestão empresarial)- Fundação Getúlio Vargas, FGV, Rio de Janeiro, 2012.

NASCIMENTO, J. C. H. B. DO; NOSSA, V.; BALASSIANO, M. O Analfabetismo Funcional e a Contabilidade: um Estudo Exploratório com Alunos Concluintes das Instituições de Ensino Superior do Estado do Espírito Santo. Sociedade, Contabilidade e Gestão, Rio de Janeiro, v. 8, n. 3, set-dez 2013.

NIYAMA, J. K. Contabilidade Internacional. 1. ed. São Paulo: Atlas, 2005.

OLIVEIRA, A. V.; LEMES. S. Nível de convergência dos princípios contábeis brasileiros e norte-americanos às normas do IASB: uma contribuição para a adoção das IFRS por empresas brasileiras. Revista de Contabilidade \& Finanças- USP, São Paulo, v. 22, n. 56, p. 155-173, maio 2011. 
OLIVEIRA, C. D. E.; JACONI, D. B. B.; ALMEIDA MOURA, F. M. DE. A percepção de dos estudantes de contabilidade sobre o impacto do IFRS no Brasil. In: IX SIMPÓSIO DE EXCELÊNCIA EM GESTÃO E TECNOLOGIA, Resende/RJ. Anais...Resende/RJ: 24 a 26 de outubro de 2012.

OLIVEIRA, C. R. de; VARELlA, P. S. A Capacitação Docente no Ensino da Contabilidade: Um estudo em IES do Norte do Paraná. In: III Encontro de Ensino e Pesquisa em Administração e Contabilidade, João Pessoa/PB.Anais...João Pessoa/PB: 20 a 22 de novembro de 2011.

PEREIRA. E. D. Convergência do IASB- Uma análise nas instituições de ensino do Distrito Federal. 2011. 96f. Dissertação (Mestrado em Ciências Contábeis)Universidade de Brasília- UNB, Brasília, 2011.

REIS, L. G. dos. NOGUEIRA, Daniel Ramos; BIM, Elvis Antônio; Convergência às Normas Internacionais de Contabilidade: uma Análise sob a Perspectiva Docente e Discente. In: XXXIV ENCONTRO DA ANPAD. Rio de Janeiro/RJ. Anais... 25 a 29 de setembro de 2010.

SANTOS, A. C.; DOMINGUES, M.J.C.S.; RIBEIRO, M.J. Um estudo sobre o nível de aderência dos cursos de Ciências Contábeis das Instituições paranaenses listadas no MEC, ao Currículo Mundial. In: VI CONGRESSO ANPCONT, Vitória/ES Anais...Vitória/ES : 20 a 22 de junho de 2011.

SANTOS, Edilene Santana; CALIXTO, Laura. Impactos do início da harmonização contábil internacional (lei 11.638/07) nos resultados das empresas abertas. RAEeletrônica, v. 9, n. 1, Art. 5, jan./jun. 2010.

SANTOS, Noema E.; QUILLIAM, William Clayton. An Interview-Based Study of Individual and Institutional Preparedness for Teaching IFRS. International Journal of Accounting and Financial Reporting, v. 3, n. 2, p. p.1-11, 2013.

SEGANTINI, G. T., et al. Uma análise crítica entre os currículos dos Cursos de Ciências Contábeis nos Países do Mercosul e o Proposto pela ONU/UNCTAD/ISAR. Revista Evidenciação Contábil \& Finanças. João Pessoa, v.1, n. 1, p. 85-98, jan./jun. 2013. 